\title{
Balancing motherhood and drug addiction: The transition to parenthood of addicted mothers
}

Journal of Health Psychology I8(3) 359-367

(C) The Author(s) 2012

Reprints and permission:

sagepub.co.uk/journalsPermissions.nav DOI: $10.1177 / 1359105312443399$ hpq.sagepub.com

@SAGE

\author{
Sofia A Silva', António P Pires', Cristina \\ Guerreiro $^{2}$ and Antónia Cardoso ${ }^{2}$
}

\begin{abstract}
This is a study about balancing motherhood and drug addiction, during the transition to parenthood. Few studies have dealt with the parental experience of drug-addicted mothers. The participants included 24 drugaddicted mothers, on methadone, with ages 25-42 and with children I-32 months of age. Semi-structured interviews were conducted and analyzed according to Grounded Theory. The mothers' main concern was the ambivalence they felt towards pregnancy/motherhood and drug addiction, which was associated with strong feelings of guilt. Confronted with this ambivalence their maternal role becomes merely functional. They focus on providing the basic care to the child, but show little willingness to talk or play. Social support, especially from the partner seems to have a positive role.
\end{abstract}

\section{Keywords}

children, drugs, experience, Grounded Theory, pregnancy

The parent-children early relationship, how it evolves and its quality are mains aspects in the psychological, social and emotional development of the child. When parental behavior is not adequate and does not correspond to the child's solicitations, it can represent a risk to his/her physical and psychological health. Being a drug-addicted parent may set a highly problematic context for parenting since it may be a risky context for the child (Barnard and Mckeganey, 2004).

In recent years, there has been a growing number of drug-addicted women of a fertile age, with a consequent growth of the number of children that are exposed to drugs in the prenatal period (Pajulo et al., 2006). Drug-addicted women are more likely to have multiple, intertwined psychosocial risks that may result in maladaptive parenting practices, with possible impact on the developmental outcomes of the children involved (Derauf et al., 2007). The time spent with children is less among drugabusing parents (Tarter et al., 1993) and the risk of child neglect increases (Chaflin et al., 1996; Forrester, 2000; Harwin and Forrester, 2002;

\footnotetext{
'Instituto Superior de Psicologia Aplicada, Portugal

2Maternidade Alfredo da Costa, Portugal

Corresponding author:

Sofia Alves da Silva, Instituto Superior de Psicologia

Aplicada, Lisbon, Portugal.

Email: sofiaalvesdasilva@gmail.com
} 
Magura and Laudet, 1996; Wasserman and Levanthal, 1993).

According to Watson and Parke (2011), there is a great deal of research on gender in relation to substance use disorders, but there is a small amount of recent qualitative research in this area looking at the experience and perceptions of the individual. In contrast to the substantial amount of literature on how individuals adjust to substance abuse, there has been little work examining how drug dependence affects (directly and uniquely) the parental functioning (Mayes and Truman, 2002). Heroin-consuming mothers frequently express inadequate feelings toward parenting, with higher probability of using negative discipline (Eiden et al., 1999). Haight et al. (2009) report that mothers, who are substance abusers, assume that their problem has an impact on their children's physical and psychological well-being, which includes: the exposure to domestic violence, to adult substance abuse and to other anti-social behaviors, as well as the loss of important relationships. In general, mothers who use drugs are commonly believed to be selfish, uncaring and neglectful with their children, although some studies have revealed that these mothers felt capable as parents, with a high valorization of motherhood and holding firm standards for childrearing (Baker and Carson, 1999; Kearney et al., 1994).

However, most of these studies do not report if these mothers are the primary caretakers (providing basic care like nourishment, cleaning, etc.) nor what is the domain of care that they mainly provide. There is also a lack of information regarding the family conditions in which their children live, that is, family structure, number of adults taking care of the child (Mayes, 1995). Because of the lack of information on parenting of drug-addicted mothers, we decided to conduct an exploratory study, using Grounded Theory. Few qualitative studies have been used to study parenting (Hardesty and Black, 1999; Taylor, 1998) although these methods, particularly
Grounded Theory, are extremely adequate to identify relevant concepts and hypotheses, and to assess social interactions and processes in a dynamic way (Glaser, 1996). The objective of this study is to contribute to a theoretical model about parenting of drug-addicted mothers, on a methadone program, with children under two years old. The empirical research questions, included one main question: 'How is it to be a drug-addicted mother?', and some subsidiary questions: 'How do they feel as mothers?', 'What are their main problems and/or concerns?', 'How do they deal with those problems on a daily basis?'

\section{Method}

\section{Participants}

Twenty-four Portuguese women, attending a supervised methadone program participated in this study. Their ages ranged from 23 to 42 years old (mean is $31 \mathrm{yr}$ ), and they had one to six children with the younger child between 1 and 32 months (mean age is 12 months 4 days). Twenty-one mothers were unemployed and all had consumed drugs (heroine/cocaine) and methadone while they were pregnant.

\section{Procedure}

The data were collected in a Maternity (Obstetrics' Service) and at an Addiction Treatment Center, in Lisbon, Portugal, after having obtained official authorizations to conduct this investigation by both institutions. After being informed about the purpose and relevance of the current study, all participants signed an informed consent form.

The interviews were conducted at the Maternity and at the Addiction Treatment Center, in private rooms. All were conducted by the same interviewer and audiotaped, taking from 60 to $90 \mathrm{~min}$ utes. The interviews started with an open question in order to motivate and allow the participants to talk freely about their own parenting experience - 'How has it been to be (child's name) mother?' 
Each interview was transcribed and analyzed (through the use of memos and notes, written after the interviews including observational data, as the interviews were done in the mothers' houses; and also through a 'constant comparison method') before the next one was made. The information gathered during the interview or during coding allowed the elaboration of new questions, that were used in the next interview. So, the data collection, the coding and analysis were concurrent.

\section{Data analysis}

The Grounded Theory is a general research methodology that uses a latent pattern analysis. It can be used with both qualitative and quantitative data, and its purpose is to produce empirically based grounded prepositions. This methodology derives from a 'discovery model', rather than a 'verification model' in which data are gathered in order to verify previous hypotheses (Glaser, 1996; Glaser and Strauss, 1971 [1967]).

In this study, a 'discovery model' seemed appropriate to fulfill its main purpose: to deepen our knowledge about the particular experience and different perspectives of mothers who are addicted to drugs and resulting in a smooth uninterrupted emergent analysis and the generation of a substantive or formal theory from data collection (Glaser, 2004). Since substance abuse can be a field of preconceptions, it seems appropriate to choose a methodology that keeps preconceived ideas from emerging, letting concepts slowly emerge from data, differently from Qualitative Data Analysis.

Through the codification process, the 'constant comparison method' and memo writing, a core variable or Basic Psychosocial Process (BPP), emerged: Functional Parenting. Several relations were found between this core category and other categories, allowing the creation of a theoretical model. The model emerged gradually, enabling the identification of contextual categories, that characterize the risks of maternal drug addiction. The theory thus explains sufficiently how people continually resolve their main concern with concepts that fit, work, have relevance and are saturated (Glaser, 2004).

\section{Results}

\section{Circumstances for substance abuse during the pregnancy}

There are some circumstances that contribute to create a favorable context to the difficulties felt by mothers who were substance abusers: a significant menstrual irregularity or even an absence of menstruation, which, along with a depreciation of sexual relations, a contraceptive negligence and heedlessness toward their own body rhythms and signs, make pregnancy an unexpected condition. Pregnancy is usually very late detected, increasing insecurity feelings, making the physical and psychological preparation, and adaptation, more difficult, and increasing the inadequacy or failure of the prenatal medical care. One mother said: 'I didn't have my period for several years, I thought I couldn't get pregnant ... never took the pill ... I never thought I could get pregnant' (\#3). So, in 16 cases, the pregnancy was not planned, something mothers did not expect in their lives, and some experienced it as a shock, as they do not feel prepared for motherhood. Some had voluntary abortions of previous pregnancies, as a way to avoid and/or delay motherhood; others did not act on it, but they thought of aborting before they made the decision to keep the baby: 'I didn't know what to do, I thought of aborting as I did before, but then I decided to have this baby' (\#4).

However, some of these mothers actually wanted to have a child. This seems to be related to a greater capacity of developing stable relationships, more often when the partners are not substance abusers or when both (mother and partner) are undergoing treatment. In these situations, the pregnancy is planned or, at least, 'allowed'. They say they were aware of the probability of pregnancy, having done nothing to avoid it. 
Despite the fact that pregnancy is usually not planned and detected later than usual, a medical supervision usually exists in order to decrease the ominous effects of drug dependence on both the mother and the child, especially because these pregnancies are frequently considered at-risk pregnancies. Pregnancy in drug addict women frequently coincides with the beginning of treatment (17 cases), by their own initiative, but in other cases it is suggested by doctors who accompany them. The pregnancy is perceived as a moment of change, representing a reason to stop consuming drugs and to begin recovery treatments. However, in spite of this wish for a change, their recovery attempts sometimes fail, resulting in relapses and substance abuse during pregnancy and even after the child's birth. The fear of consequences for the child is often present: 'I was always thinking ... if she was ok, all I wanted was that she'd be a healthy baby' (\#12).

\section{Ambivalence between addiction and pregnancy/parenting}

Pregnancy and motherhood is characterized by a strong ambivalence between addiction and parenting. Contradictory feelings and thoughts tend to arise: on one hand deep feelings of despair, anguish and anxiety emerge, on the other hand, pregnancy and motherhood are simultaneously moments of hope, in which mothers stop to think, and begin to see their child as a salvation:

'I didn't know what to do, I felt I couldn't stop taking drugs, how could I be a good mother? Afterwards I could see things more clearly: I could stop it for this child, my baby would save me and it gave me strength enough to carry on' (\#2)

However, they often see the child as an extension of themselves, where they place expectations and roles that the baby cannot accomplish: 'My son helped me very much in my addiction. I felt I was more responsible and he gave me strength to keep going on with my life and to recover from drugs' (\#2).
These women usually feel they cannot cope with the ambivalence, entering an exhausting cycle of feelings of guilt, which we called guiltiness/non-guiltiness. They frequently blame themselves for consuming during the pregnancy/motherhood, for consumptions prior to the pregnancy and for relapses. They fear for serious consequences for the baby's health, and await the child's birth with significant anxiety.

After birth and during infancy, eventual addiction's consequences on the child (e.g. prematurity, abstinence syndrome, breathing disorders, feeding disorders, sleep disorders, hyperactivity, malformations) make these mothers feel guilty. One of them said: 'I used drugs when I knew I was pregnant, sometimes I relapsed and I felt very scared and guilty for the consequences it could bring to my child' (\#20). Nevertheless, they concomitantly reveal a need of counteracting this guiltiness by justifying their need for taking drugs. So, they speak about being impotent toward the need of consuming, feeling incapable of control. Some of them use 'normalization' as an argument, stating that no drug addict would be able to avoid consuming, as a way of relieving themselves from the responsibility.

When symptoms arise in the newborn, women try to minimize them as much as they can, using normalization, that is, considering themselves as similar to any other woman, in a constant search for self-valorization. They repeat the same process with their children, who they consider normal by comparison to other children (child's valorization).

\section{Functional (minimal) parenting}

In most cases, especially regarding the mothers who began treatment a year or two before the pregnancy, the parental role is developed with satisfaction. These mothers enjoy being with their children and even miss them when they go to kindergarten.

However, some mothers continue consuming during the pregnancy and even after giving birth. Also, the relationships with the partners 
are sometimes disruptive, leading to the separation of the couple. In these families, the initial period of parenting is difficult. Faced with a constant ambivalence, there is very little space for the mother role, and a central process that we have called 'Functional (or minimal) Parenting' arises. This means that, in these women's personal universe, parenting represents a functional part of their lives, an almost distorted role, seen as a mere function. In this way, the 'Functional Parenting' becomes evident in some strategies and behaviors: mothers describe several difficulties regarding the maternal role (like limits and rule setting, being patient or meeting the physical and emotional needs of the child). In the mothers' words: 'She is very stubborn, she has a strong personality, she seldom does what I tell her to do!' (\#8) or 'I get lost when she cries, I don't know what to do!' (\#1). Confronted with these difficulties they make a huge effort to keep on doing what they think is essential, in their role as a parent. They try not to deprive their child from the satisfaction of basic needs because of their drug addiction, and the child is even referred to as a priority (i.e. the financial resources have to meet the child's basic needs first, such as nurturing, dressing, hygiene, and only after that can the mother's addiction needs be met). Sometimes, these mothers consume minimum dosages to prevent them from feeling physical and psychologically bad and to allow them to be vigilante and take care of their child, dealing with his/her most immediate needs and with any eventual accidents that may occur at home. The hangover, when it occurs, is sort of a controlled hangover, in which mothers wait, suffering, for a new chance to consume. In their descriptions of the parent-child relationships, they mostly refer to the basic care (bathing, dressing, feeding, sleeping, medical follow-up) and the effort they make to meet these needs: 'I have given my children all they need, although I could be relapsing and making a huge effort to keep on taking care of them' (\#1). They refer to a high level of fatigue and a lack of patience/ availability, trying to assure basic care taking of the child as soon as they get home.
This lack of availability and patience seems to increase when the child gets older and starts having a more interactive and demanding relationship with the surrounding environment, and the people in it. These mothers also reveal a great incapacity in dealing with the child's emotional needs and demands, and in coping with behavioral problems. They also mention difficulties on limit-setting, and their constant drought of patience sometimes has serious consequences on the child's basic care. Some mothers see the pregnancy and motherhood as a motivation/salvation, in which the pregnancy time and the children are part of their recovery, becoming somewhat of an extension of themselves and they feel it as a fulfillment: 'She was my life-boat, a motivation to begin my recovery' (\#2). They say that the new situation is 'a sign' and a motivation to make changes in their lives. While prior to the pregnancy they were only focused on consuming, and were overcome by the addiction, now they feel the need to think about their children, who become drug substitutes.

Despite the ambivalence they feel regarding the time they have to devote to the child, and cannot dedicate to themselves any more, they believe that it is precisely that amount of time that will keep them busy and their minds off the drugs, in an efficient enough way so that they do not go through relapses. The feelings of ambivalence and turmoil disappeared in most of the cases, leaving only some remainders a few months after birth, which depend on some intervening factors, which seem to have influence on the change from an ambivalent mothering into a healthier parental role.

\section{Intervening factors: family support to parental role}

In these situations, due to the common instability involved, it is frequent for the parents of the addicted mothers to take care of their grandchildren, and provide a home so that the mothers have 'somewhere to live'. In 11 cases, grandparents were taking care of the child most of the time. The grandmother is often the primary 
caretaker, carrying out the mother's role: 'When she starts crying I call my mother, she feeds and bathes her' (\#22). This allows the mother more availability, however it also may have its problems, such as excessive control by the grandparents (over both their daughter and grandchildren), which may result in a loss of independence and autonomy for them, a lack of space and frequently generational conflicts.

Besides the support given by the grandparents, some women refer to other support given by other people (uncles, neighbors, friends). This other support is essentially financial and material, as most of these mothers are unemployed, but also includes psychological support.

The partner's support is identified by these women as one of the most important types of support. Some of the partners, whether they are consumers or not, help these mothers during the pregnancy and feel happy with the child's birth, which is very important for them. This support is also provided by the trust partners place on these women, during the initial period of difficulties. Drug-addicted mothers who have their partners' emotional and/or financial support, say that it is a big help in all the processes of change, especially when their partners shared responsibilities and helped taking care of the children. Addicted partners can also be a good help when both decide to start the treatment, when they know they are going to be parents, which is a double stimulus to stop consuming drugs. However, not all partners are this supportive; some women refer to a lack of support, usually in the context of a difficult marital relationship, that results many times in separation. In these cases, there is a growing lack of communication and support during pregnancy, at the delivery moment and in helping with the child's care.

If partners are consuming during pregnancy and after birth while women are undergoing treatment, their relationship becomes impossible, triggering the separation: 'When I decided to begin treatment, we both did. We had tried before, each one alone, and we had failed, it's impossible to begin treatment when one is doing drugs and the other wants to leave that life' (\#17). Without this support mothers feel a stronger social isolation, becoming less available and patient toward their child, and completing the treatment with success, as well as recovering, is more difficult. Social isolation and loneliness also arise, because substanceabusing women who stop consuming move away from their social group, as a way of avoiding relapses.

Furthermore, the healthcare professionals' support is also of great importance. These mothers value doctors and nurses who try to protect, help, support and understand them, making them feel that they are good mothers, and that they know how to take care of their children. They make a clear distinction between these 'helpful professionals' and the others, who are considered incompetent and discriminating professionals, that treat them as if they are impaired in their maternal role, and looking at them differently, as people who do not deserve their attention, thus increasing the burden of social stigma: 'I'm tired of being discriminated ... from the moment I stepped in the emergencies service and they knew I was a drug addict, they treated me differently' (\#6).

Other aspects that seem to transform these parents' initial ambivalence into parental healthier behavior are: starting the treatment during or even before pregnancy; consuming during pregnancy and infancy; the child's and mother's ages. As ambivalence decreases as the children get older, a healthier and more adapted parental role seems to slowly emerge. According to these results, mothers of children older than six months, who began the treatment early, before or during early pregnancy and did not have relapses, are more adapted to the parental role, and more attached emotionally and available. Although they see motherhood as a transition, they face it as a good responsibility and a fulfilled purpose.

\section{Discussion}

Drug-addicted mothers clearly reveal a strong ambivalence between dedicating themselves to 
their children and continuing consuming drugs, usually associated to a feeling of guilt. In those periods, primary care seemed to be assured, however motherhood seemed reduced to functional aspects. A small group, especially those who did not have social support, continued revealing difficulties, concerning social and didactic care, as well as in imposing limits. On the one hand, the results revealed that these mothers adapted to their parenting role as time went by, on the other the turbulence that most had been through could not be ignored.

Facing a constant ambivalence, little room was left to fulfill their role as mothers. The Primary Maternal Care - an expression first used by Winnicott (2000 [1956]: 399-405) to describe a temporary phase of extreme sensibility toward the baby - seemed difficult to take place. Thereby, a central process, which we called Functional Parenting, emerged. This process is characterized by a distortion of the parenting role's characteristics that are seen merely as functional, expressed through many of the mother's behaviors (focusing on basic care, being impatient and lacking availability, giving the child total priority and avoiding depriving him/her of basic care). Actually, these mothers do not see Functional Parenting as something negative, since they believe that basic care is all they have to do, neglecting the possibility of a more emotionally engaged relationship. These results are consistent with other studies that identified drug-abusing mothers as less emotionally engaged and responsive to their infants (Gottwald and Thurman, 1994), showing a less positive involvement (Kandel, 1990) or a lower maternal involvement (Suchman and Luthar, 2000). We believe our study may help to understand neglect situations that occur in these families, as well as why the child is neglected. Rather than a victim of physical or sexual abuse, the primary reason for intervention by social services in these families where one or both parents are drug addicts is neglect.

The fact that these mothers attend methadone programs, may explain why we found no cases where basic care was absent. During periods of intense drug use children can be victims of different types of situations, such as improper feeding, clothing or caring (Barnard and Mckeganey, 2004), lapses in hygiene and inconsistent regard for the child's safety and supervision (Kroll and Taylor, 2003). In this study mothers frequently referred to the consequences of drug abuse on their children: abstinence syndrome; low weight or even prematurity; respiratory problems; feeding and sleeping difficulties; as well as crying, agitation and restlessness. However, they do not acknowledge the existence of relationship problems with their children, denoting their difficulty to consider anything beyond basic care as a main aspect in the dyadic relationship. This does not mean that the child becomes harmed, since sometimes other relatives (usually grandmothers) replace the mothers in their parenting functions. The recovery attempts are so invasive, taking most of their strength and availability, that whatever is left to dedicate to their children becomes minimal. While trying to suppress their own difficulties, they ignore some of the child's needs. Not all mothers reveal the same degree of ambivalence, or the same difficulties in the transition from pregnancy to the beginning of motherhood, so it was not possible to find out what actually differentiates the mothers' behaviors.

It was possible to identify some factors involved, such as the period of abstinence, if it started before or after the pregnancy; the presence or absence of a partner, kind of social support (namely by grandmothers) they receive in the everyday care of the child. However, it is not yet possible to understand the importance of each one of these factors.

Although we found great internal difficulties in the process of becoming a mother, when recovering from drug addiction, these difficulties do not seem to have much of an external impact on parenting, in most of the mothers in methadone programs, confirming Hogan and Higgins' (2001) statement when they say that, during periods of relative stability (whether drug free or on a controlled dosage), the impact 
of parental drug use on the family functioning might be minimal.

Nevertheless, it seems to us, that the minimal impact on parenting occurs in situations of longer and more stable engagement in recovery programs, and mostly results from the intervening factors like social support and partner support, which seem to have a main role in the process of becoming a mother, allowing these mothers to overcome difficulties in their relationships with their children.

Conceptually understood as a development crisis, motherhood, in addicted mothers, can be of extreme importance to eneehance a change, such is the opportunity that pregnancy and motherhood represent to them. With adequate clinic intervention, this moment can be of great motivation to change these mothers' consumption patterns, and their whole lifestyle, motivating them to enter a treatment program.

We would like to emphasize that the results of this analysis are unique to the particular participants of this study.

It was possieble to identify the factors involved in the ambivalence and difficulties in the transition to motherhood, such as the length of abstinence, if this abstinence started before or after pregnancy; the presence or absence of a male partner, or what kind of support, namely by grandmothers, do they receive in day-to-day care. However, it is not still possible to understand the importance of each factor. It would be interesting to investigate in future studies their family history, as well as the bonding characteristics experienced with their own mothers. It would be interesting also to observe parenting behavior in a longitudinal study in order to complement the retrospective approach of the present study.

\section{Competing Interests}

None declared.

\section{References}

Baker P and Carson A (1999) 'I take care of my kids': Mothering practices of substance-abusing women. Gender and Society 13(3): 347-363.
Barnard M and Mckeganey N (2004) The impact of parental problem drug use on children: What is the problem and what can be done to help? Addiction 99: 552-559.

Chaflin M, Kelleher K and Hollenberg J (1996) Onset of physical abuse and neglect: Psychiatric substance abuse and social risk factors from prospective community data. Child Abuse and Neglect 20: 191-203.

Derauf C, LaGasse LL, Smith LM, et al. (2007) Demographic and psychosocial characteristics of mothers using methamphetamine during pregnancy: Preliminary results of the infant development, environment, and lifestyle study (IDEAL). American Journal of Drug and Alcohol Abuse 33(2): 281-289.

Eiden RD, Peterson M and Coleman T (1999) Maternal cocaine use and the caregiving environment during childhood. Psychology of Addiction Behaviors 13(4): 239-302.

Forrester D (2000) Parental substance misuse and child protection in a British sample: A survey of children on the child protection register in an inner London district office. Child Abuse Review 9: 235-246.

Glaser BG (1996) Gerund Grounded Theory: The Basic Social Process Dissertation. Mill Valley, CA: Sociology Press.

Glaser BG (2004) Remodeling Grounded Theory. The Grounded Theory Review 4(1): 1-24.

Glaser B and Strauss A (1971 [1967]) The Discovery of Grounded Theory. Chicago, IL: Aldine Atherton.

Gottwald RS and Thurman SK (1994) The effects of prenatal cocaine exposure on mother-infant interaction and infant arousal in the newborn period. Topics in Early Childhood Special Education 14(2): 217-231.

Haight W, Carter-Black J and Sheridan K (2009) Mothers' experience of methamphetamine addiction: A case-based analysis of rural, Midwestern women. Children and Youth Services Review 31: 71-77.

Hardesty M and Black T (1999) Mothering through addiction: A survival strategy among Puerto Rican addicts. Qualitative Health Research 9(5): 602-619.

Harwin J and Forrester D (2002) Parental Substance Misuse and Child Welfare: A Study of Social Work with Families in Which Parents Misuse Drugs or Alcohol. Interim report. London: Nuffield Foundation. 
Hogan D and Higgins L (2001) When Parents Use Drugs: Key Findings from a Study of Children in the Care of Problem Drug Using Parents. Dublin: Children's Research Centre, Trinity College.

Kandel D (1990) Parenting styles, drug use and children's adjustment in families of young adults. Journal of Marriage and the Family 52: 183-196.

Kearney MH, Murphy S and Rosenbaum M (1994) Mothering on crack cocaine: A Grounded Theory analysis. Social Science and Medicine 38(2): 351-361.

Kroll B and Taylor A (2003) Parental Substance Misuse and Child Welfare. London: Jessica Kingsley Publishers.

Magura S and Laudet AB (1996) Parental substance abuse and child maltreatment: Review and implications for intervention. Children and Youth Services Review 18(3): 193-220.

Mayes L (1995) Substance abuse and parenting. In: Bornstein MH (ed.) Handbook of Parenting. Mahwah, NJ: Lawrence Erlbaum, vol. 4, pp. 101-125.

Mayes LC and Truman SD (2002) Substance abuse and parenting. In: Bornstein MH (ed.) Handbook of Parenting. Mahwah, NJ: Lawrence Erlbaum, 2nd edn, vol. 4, pp. 329-360.

Pajulo M, Suchman N, Kalland M and Mayes L (2006) Enhancing the effectiveness of residen- tial treatment for substance abusing pregnant and parenting women: Focus on maternal reflective functioning and mother-child relationship. Infant Mental Health Journal 27(5): 448.

Suchman NE and Luthar SS (2000) Maternal addiction, child maladjustment and sociodemographic risks: Implications for parenting behaviours. Addiction 95: 1417-1428.

Tarter R, Blackson T, Martin C, Loeber R and Moss H (1993) Characteristics and correlates of child discipline practices in substance abuse and normal families. American Journal of Addiction 2(1): 18-25.

Taylor A (1998) Needlework: The lifestyle of female drug injectors. Journal of Drug Issues 28(1): 77-91.

Wasserman DR and Levanthal JM (1993) Maltreatment of children born to cocaine-dependent mothers. American Journal of Diseases in Children 147: 1324-1328.

Watson L and Parke A (2011) Experience of recovery for female heroin addicts: An Interpretative Phenomenological Analysis. International Journal of Mental Health and Addiction 9(1): 102-117.

Winnicott DW (2000 [1956]) Da pediatria à psicanálise. Rio de Janeiro: Imago. 